\title{
Development of New Selenopyrylium Salts for Its Application in PDT ${ }^{+}$
}

\author{
Antonio J. Galera-Carrillo *, Jonathan Ramírez Cárdenas, Antonio Franconetti \\ and Francisca Cabrera-Escribano \\ Departamento de Química Orgánica, Facultad de Química, Universidad de Sevilla, Apartado de Correos No. \\ 1203, 41071 Sevilla, Spain; email1@gmail.com (J.R.C.); email2@gmail.com (A.F.); email3@gmail.com (F.C.-E.) \\ * Correspondence: agalera@us.es; Tel.: +34-954-556-868; Fax: +34-954-624-960 \\ + Presented at the 24th International Electronic Conference on Synthetic Organic Chemistry, 15 November- \\ 15 December 2020; Available online: https://ecsoc-24.sciforum.net/.
}

Published: date

\begin{abstract}
Among the great challenges facing the Society is the search for solutions to cancer. This disease presents high cellular oxidative stress, as a result of the imbalance between the oxidizing species generated in the cells and antioxidant compounds [1] One of the strategies used in the treatment of cancer is based on the use of Photodynamic therapy (PDT). PDT is a safe and noninvasive technique for the treatment of different types of cancer in diverse locations, as well as noncancer diseases [2]. Thus, our research focuses on search for new compounds with potential application in this field, among which the selenopyrylium salts stand out.
\end{abstract}

Keywords: selenopyrylium salts; PDT; photosensitizer

\section{Introduction}

Nowadays, treatment of cancer is approached through different strategies, among wich PDT can be mentioned. PDT consists of the local or systemic application of a photosensitive compound (the photosensitizer), which accumulates mainly in the pathological tissues. Photosensitive molecules absorb light of the appropriate wavelength, initiating the activation processes that lead to the selective destruction of tumour cells [3,4].

An adequate photosensitizer must obey a number of features such as maximum absorption length between 600 and $800 \mathrm{~nm}$, minimum absorption length between 400 and $600 \mathrm{~nm}$, high purity and stability at room temperature, and high selectivity with tumour tissues, among others [5]. In this context, selenopyrylium salts emerge as potential candidates to photosensitizers due to fit with most of these features.

Therefore, the aims in the present work are the synthesis and characterization of monocationic selenopyryllium salts, using a methodology that does not involve organometallic reagents, and the evaluation of their photophysical properties for their possible application as photosensitizers in PDT.

\section{Experimental Methods}

All chemicals were purchased and used without further purification. Evaporations were conducted under reduced pressure. TLC was performed on silica gel plates (MN ALUGRAM Xtra SIL G/UV 254). All new compounds were synthesized following the below general procedure. Detection of compounds was accomplished with UV light $(254 \mathrm{~nm})$ and characterization by ${ }^{1} \mathrm{H}$ and ${ }^{13} \mathrm{C}$ NMR and Mass spectrometry. 


\subsection{Example of Synthesis of Selenopyrylium Salt}

2,4,6-Triphenylselenopyrylium Perchlorate

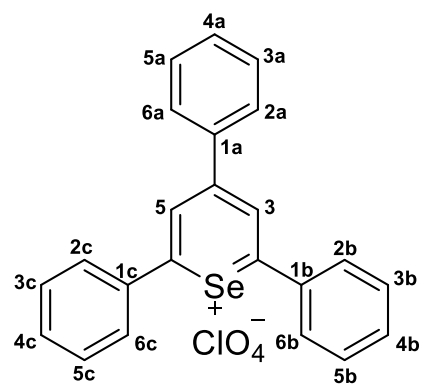

To a solution of pyrylium tetrafluoroborate salt $(1 \mathrm{mmol})$ previously solved in toluene $(5 \mathrm{~mL})$ and prepared in a sealed tube, Woollins' reagent $(1 \mathrm{mmol})$ was added. The mixture was stirred at 150 ${ }^{\circ} \mathrm{C}$ for $24 \mathrm{~h}$, monitored by TLC (4:1 Cyclohexane:EtOAc). After cooling, the resulting mixture was filtered off and the rest in the tube was washed with $\mathrm{EtOH}(2 \times 10 \mathrm{~mL})$ and filtered as well. The solvent of the filtered was then coevaporated with $\mathrm{EtOH}$ under vacuum. The resulting solid was redissolved in $\mathrm{CH}_{2} \mathrm{Cl}_{2}(5 \mathrm{~mL})$ and $\mathrm{HClO}_{4}(50 \mu \mathrm{L})$ was added dropwise, leaving the mixture stirring during $1 \mathrm{~h}$. Firstly, treatment with diethyl ether $(10 \mathrm{~mL})$ and cooling in the fridge during $1 \mathrm{~h}$ led to the formation of a precipitate which was filtered off and it led the separation of pyrylium (solid) and selenopyrylium salt (filtrate). After that, evaporation of filtrate and treatment with $\mathrm{CH}_{2} \mathrm{Cl}_{2}(10 \mathrm{~mL})$ and cooling again in the fridge during $1 \mathrm{~h}$ led to the separation of the rest of subproducts (solvent) and the desired compound $(30 \mathrm{mg}, 25 \%)$ as an orange solid.

${ }^{1} \mathrm{H}$ NMR (500 MHz, acetone- $\left.d_{6}\right): \delta 9.24$ (s, 2H, H-3 and H-5), 8.42 (d, 2H, J = 7.4 Hz, H-2a and H6a), 8.30 (d, 4H, J = 7.4 Hz, H-2b, H-6b, H-2c and H-6c), 7.82 (m, 9H, H-3a, H-4a, H-5a, H-3b, H-4b, H$5 b, \mathrm{H}-3 \mathrm{c}, \mathrm{H}-4 \mathrm{c}$ and $\mathrm{H}-5 \mathrm{c})$.

\section{Results and Discussion}

The preparation of selenopyrylium salts has been a laborious process since, although selenium chemistry has advanced a lot in recent years, its reactivity is not as well known as that of carbon.

Initially, two routes for the synthesis of these compounds were contemplated. The first one consists of an opening-closing process through a 1,5-dicarbonyl intermediate. The second route is a one pot reaction between the pyrylium salt and a selenant agent to obtain the desired product (Scheme 1).

After a great variety of trials in each one of the proposed routes, it was possible to optimize a methodology for the adequate obtaining of these compounds. This methodology was based on the reaction of the selenopyrilium salt with Woollin's reagent under high temperature (Scheme 2).

Some examples of the selenopyrylium salts prepared (1-4) are collected in Table 1 . These compounds were characterized by ${ }^{1} \mathrm{H}$ NMR, ${ }^{13} \mathrm{C}$ NMR and HRMS. 


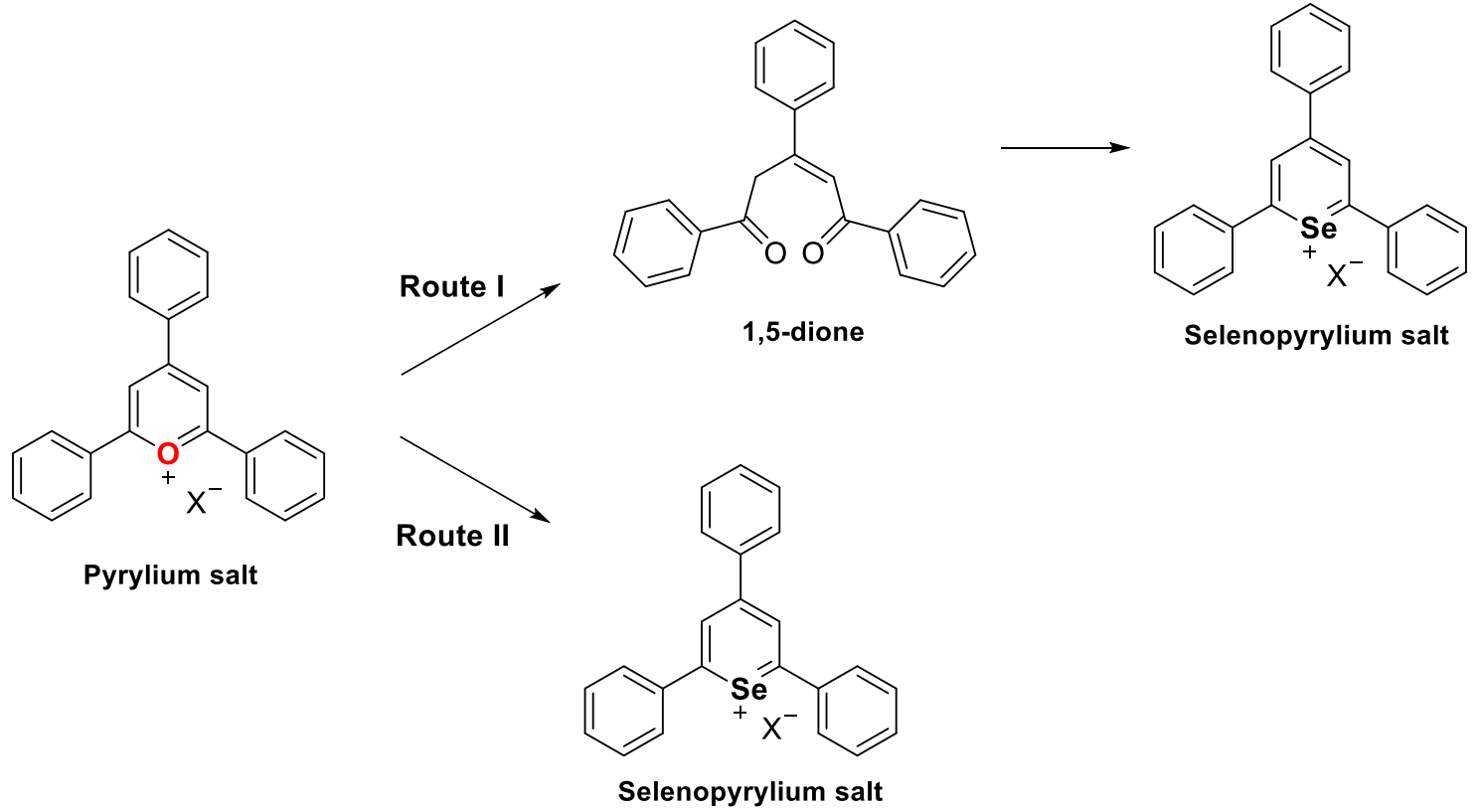

Scheme 1. Synthesis of selenopyrylium salts by reaction with WR.

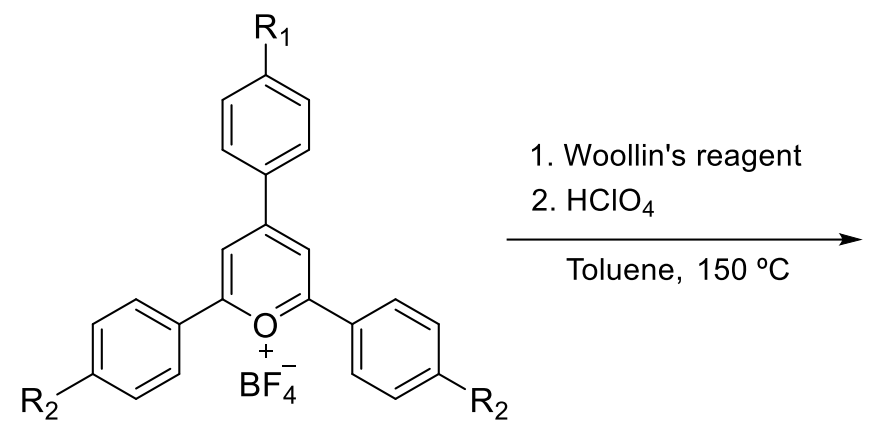<smiles></smiles>

Scheme 2. Synthesis of selenopyrylium salts by reaction with WR.

Table 1. Some selenopyrylium salts prepared.

\begin{tabular}{cccc}
\hline Selenopirilio & $\mathbf{R}_{\mathbf{1}}$ & $\mathbf{R}_{\mathbf{2}}$ & Yield (\%) \\
\hline $\mathbf{1}$ & $\mathrm{H}$ & $\mathrm{H}$ & 50 \\
$\mathbf{2}$ & $\mathrm{F}$ & $\mathrm{H}$ & 46 \\
$\mathbf{3}$ & $\mathrm{Ph}$ & $\mathrm{Me}$ & 37 \\
$\mathbf{4}$ & $\mathrm{H}$ & $\mathrm{Me}$ & 52 \\
\hline
\end{tabular}

Due to the structural similarity of the selenopyrilium salt and its starting counterpart, comparative analyzes of the ${ }^{1} \mathrm{H}$ NMR spectra were carried out in the same solvent with respect to the starting pyrylium salt during the purification process. Furthermore, HRMS-ESI allowed us to distinguish the cation of selenopyrylium salt from the pyrylium one during the purification.

The symmetric selenopyrylium salts obtained $1-4$ show in the ${ }^{1} \mathrm{H}$ NMR spectrum in DMSO- $\mathrm{d}_{6}$ a characteristic signal which consists in a singlet in the range of 9.30-8.93 ppm for the two equivalent protons $\mathrm{H}-3$ and $\mathrm{H}-5$ of the selenopyrilium ring.

\section{Conclusions}

New selenopyrylium salts have been prepared and characterized by two different methodologies: starting from pent-2-en-1,5-diones and starting from selenopyrilium salts. Thus, it has been found that the most efficient methodology is the one that starts from pyrylium salts, since it involves fewer reaction steps and, in turn, offers significantly higher yields. Furthermore, the 
photophysical properties of the compounds obtained are currently being studied in order to verify their applicability in PDT.

Acknowledgments: The authors thank the Junta de Andalucía (2011/FQM-142, and Project P09-AGR-4597); Spanish Ministerio de Economía, Industria y Competitividad (MINECO), Spain (CTQ2016-78703-P); A.J. GaleraCarrillo also thanks Universidad de Sevilla (PEJUS-2, 2017-2-EJ-070) for funding support. The authors also thank the CITIUS, Universidad de Sevilla, for the facilities.

\section{References}

1. Poljsak, B. Oxid. Med. Cell Longev. 2011, 2011, 194586.

2. Luo, D.; Carter, K.A.; Miranda, D.; Lovell, J.F. Adv. Sci. 2017, 4, 1600106.

3. Schmitt, F.; Juillerat-Jeanneret, L. Anticancer Agents Med. Chem. 2012, 12, 500-525.

4. Lee, B.I.; Chung, Y.J.; Park, C.B. Biomaterials 2019, 190-191, 121-132.

5. Benov, L. Med. Princ. Pract. 2015, 24, 14-28.

Publisher's Note: MDPI stays neutral with regard to jurisdictional claims in published maps and institutional affiliations.

(C) 2020 by the authors. Submitted for possible open access publication under the terms and conditions of the Creative Commons Attribution (CC BY) license (http://creativecommons.org/licenses/by/4.0/). 